\title{
Efficiency of 48h vs. 24h Injection of Parathyroid Hormone for Amelioration of Osteopenic Spine Properties in Male Rats
}

\author{
Marina Komrakova*,1,\#, Ewa K. Stuermer ${ }^{\#, 2}$, Armin Sturm ${ }^{1}$, Ulrich Schmelz ${ }^{3}$, Mohammad Tezval ${ }^{1}$, \\ Klaus M. Stuermer ${ }^{1}$ and Stephan Sehmisch ${ }^{1}$
}

\author{
${ }^{I}$ Department of Trauma Surgery and Reconstructive Surgery, University Medical Center Goettingen, Robert-Koch Str. \\ 40, 37075 Goettingen, Germany \\ ${ }^{2}$ Institute for Research in Operative Medicine, Faculty of Health-School of Medicine, Witten/Herdecke University, \\ Ostmerheimer Str. 200, 51109 Cologne, Germany \\ ${ }^{3}$ Department of Medical Microbiology, Subdivision of General Hygiene and Environmental Health, University of \\ Goettingen, Humboldallee 34a, 37073 Goettingen, Germany
}

\begin{abstract}
Daily application of parathyroid hormone (PTH 1-34) is used for treatment of osteoporosis. It was investigated whether orchiectomy-induced osteoporotic changes in spine can be ameliorated by every $48 \mathrm{~h}$ administration of PTH in aged male rats. Eight-month-old male Sprague-Dawley rats were sham operated $(n=24)$ or orchiectomized (Orx, $n=36)$ and maintained untreated over 12 weeks. Thereafter, both tibia underwent transverse metaphyseal osteotomy (Komrakova et al. 2011, J Endocrinol; 209:9-19) and rats were divided into 5 groups treated s.c. as follows: 1) sham vehicle; 2) sham PTH every 24h (PTH/24h); 3) Orx vehicle; 4) Orx PTH/24h; 5) Orx PTH every 48h (PTH/48h). PTH dosage was 40 $\mu \mathrm{g} / \mathrm{kg} \mathrm{BW}$ per injection. After 5 weeks, lumbar vertebral bodies were used in computed tomographical, biomechanical, histomorphological, ashing and gene expression analyses. Cortical and trabecular densities, biomechanical properties, serum osteocalcin level increased significantly after PTH treatments in all groups (yield load, sham: $232 \pm 17 \mathrm{~N}$, sham PTH/24h: $376 \pm 12 \mathrm{~N}$, Orx: $239 \pm 16 \mathrm{~N}$, Orx PTH/24h: $324 \pm 31 \mathrm{~N}$, Orx PTH/48h: $297 \pm 17 \mathrm{~N})$. Bone inorganic weight enhanced after daily PTH application in Orx rats. Bone gene expression did not differ $(\mathrm{P}>0.05)$ among the groups. Both PTH administration regimes ( $24 \mathrm{~h}$ and $48 \mathrm{~h}$ ) improved impaired bone structure in osteopenic rats. Every $48 \mathrm{~h}$ application was less effective, however, it improved bone properties to the level observed in healthy (sham) rats. Considering limitation of daily treatments known in humans, these results may be useful for further clinical studies.
\end{abstract}

Keywords: Biomechanics, Gene expression, Lumbar spine, Osteoporosis, Parathyroid hormone.

\section{INTRODUCTION}

Evaluation of the lumbar vertebrae is essentially important in the treatment of osteoporosis and osteoporosis related fractures. Spine fractures lead to continuous back pain and spinal deformity that predicts further vertebral and non-vertebral fractures [1].

Hypogonadism or deprivation of androgen by surgical or chemical treatment in men can lead to developing of osteoporosis and increased fracture occurrence [2]. The mortality rate associated with fractures is higher in men than in women [3], though women are at greater risk of developing of osteoporosis. Statistical studies predicted that one out of 5 men aged over 50 would have an osteoporosisrelated fracture [4] and this figure would rise [5]. Despite the statistics and the availability of treatment options, osteoporosis is still under-recognized in men, the treatment remains inadequate and the most studies are still conducted on female subjects $[3,6]$.

*Address correspondence to this author at the Department of Trauma Surgery and Reconstructive Surgery, University Medical Center Goettingen, Robert-Koch Str. 40, 37075 Goettingen, Germany; Tel: +49 551 396073; Fax: +49 55139 8991; E-mail: komrakova@yahoo.com

\#The first two authors equally contributed to the work.
Currently, human parathyroid hormone (hPTH 1-84) and its teriparatide, recombinant hPTH 1-34, are being used as anabolic agents for treatment of severe osteoporosis in women and men [7]. The parathyroid hormone regulates serum calcium level and stimulates new bone formation when applied intermittently (by daily injections) [8]. The mechanisms by which intermittent administration produce anabolic effects are of considerable interest, however, they are not completely understood so far. Intermittent PTH administration directly activates survival signaling in osteoblasts, attenuates osteoblast apoptosis, thereby increasing osteoblast number, bone formation rate and bone mass, but does not affect osteoclast number [9].

PTH has been reported to increase spine bone mineral density (BMD) when applied at several dosages, for any duration, in different clinical situations and in combinations with other agents [10]. However, PTH treatment has significant limitations because of the high cost and daily subcutaneous administration [11]. In animal based studies, various regimes of PTH administration were used. However, the results obtained from these trials show a variation and it is difficult to reach a definitive conclusion $[12,13]$. Recent study showed that PTH administration improved bone healing in both healthy and ovariectomy-induced osteopenic 
rats regardless of application frequency (7, 5 times per week or every other day) [14]. Part of the present study has been published previously $[15,16]$. It was shown, that in aged males the effect of PTH on bone healing was less when it was applied with less frequency (every day vs. every other day) [15]. The proximal femur responded to PTH treatments positively showing improved biomechanical properties, mineral content and trabecular bone parameters [16]. Thus, PTH improved tibia healing and reversed structural impairment in femur in male rats. However, evaluation of the lumbar vertebral region is also extremely important. Moreover, various responses to PTH by different anatomic sites have been reported [10, 14, 17].

In the present study we investigated whether orchiectomy-induced osteoporotic changes in spine can be ameliorated by administration of PTH every $48 \mathrm{~h}$ in aged male rats. Comparisons were made with PTH applied at $24 \mathrm{~h}$ interval.

\section{MATERIAL AND METHODS}

The animal study protocol was approved by the local regional government and conformed to the German animal protection laws.

Eight-month-old male Sprague-Dawley rats (Janvier, Le Genest-Saint-Isle, France) were bilaterally sham operated (n $=24)$ or orchiectomized $(n=36$, Orx $)$ under i.p. ketamine and xylazine anesthesia $(60 \mathrm{mg}$ and $8 \mathrm{mg} / \mathrm{kg}$ of body weight (BW), respectively). After 12-week development of osteoporotic changes in bone, ketamine-xylazineanesthetized rats underwent a transverse osteotomy of tibia metaphysis [18]. Data on osteotomy healing have been published previously [15].

PTH (1-34) treatments began on the next day after osteotomy and continued for 5 weeks. In group 1, shamoperated rats (sham) received vehicle $(0.9 \% \mathrm{NaCl})$ every 24h. In group 2, sham rats were treated with PTH every $24 \mathrm{~h}$ (sham PTH/24h). In group 3, Orx rats were given vehicle every $24 \mathrm{~h}$ (Orx). In group 3 and 4, Orx rats were treated with PTH either every $24 \mathrm{~h}$ or every $48 \mathrm{~h}$ (Orx PTH/24h or Orx $\mathrm{PTH} / 48 \mathrm{~h}$, respectively). A dosage of PTH was $40 \mu \mathrm{g} / \mathrm{kg} \mathrm{BW}$ per injection.

The labeling of new bone formation was done with 4 fluorochrome dyes applied: xylenol orange $(90 \mathrm{mg} / \mathrm{kg} \mathrm{BW})$ on day 13 , calcein green $(10 \mathrm{mg} / \mathrm{kg} \mathrm{BW})$ on day 18 , alazarin complexone (30 mg/kg BW) on days 22 and 24 and tetracycline $(25 \mathrm{mg} / \mathrm{kg} \mathrm{BW})$ on day 35 after beginning of treatments, respectively. All injections were done subcutaneously.

After 5 weeks of treatments, $\mathrm{CO}_{2}$-anesthetized rats were decapitated. Immediately, the lumbar vertebral bodies were dissected free of soft tissues and spinal cord and stored at $20^{\circ} \mathrm{C}$ until further analyses. The sixth vertebral body (L6) was stored at $-80^{\circ} \mathrm{C}$ for analyses of gene expression.

\section{Flat-Panel Volume Computed Tomography (fpVCT)}

The third vertebral body (L3) was scanned using an fpVC tomograph (GE Global research, Niskayuna, NY, USA). Body of vertebra was analyzed on an Advantage Workstation (Version 4.2, General Electric Healthy Care, Milwaukee, WI, USA). Processes, laminae and endplates were not included in the analysis. Cortical and cancellous bone mineral densities were calculated using hydroxyapatite standards of several mineral densities [19].

\section{Ashing}

The second vertebral body (L2) was dried in a muffle oven at $110^{\circ} \mathrm{C}$ for $24 \mathrm{~h}$ and then ashed at $750^{\circ} \mathrm{C}$ for $1 \mathrm{~h}$. Ash weight was expressed relative to cylindrical volume of vertebral body. Calcium content was determined using atomic absorption spectrometer (4100, PerkinElmer, Germany). Orthophosphate content was assayed by colometric method (spectral photometer DM4, Zeiss, Germany).

\section{Biomechanical Analyses}

The fourth vertebral body (L4) was tested biomechanically using testing device (Zwick/Roell, Ulm, Germany). The load was applied at the caudal end plate along the cranial-caudal axis of the vertebral body [20]. Stiffness, yield load and maximal compressive strength (Fmax) were determined.

\section{Histomorphological Analyses}

The entire first vertebral body (L1) was subjected to the sequential ascending concentrations of ethanol, embedded in methylmethacrylate and cut sagitally at a thickness of 150 $\mu \mathrm{m}$ using diamond saw microtome (Leica SP 1600, Leica Instriments $\mathrm{GmbH}$, Nussloch, Germany). Fluorochrome labeled sections were analyzed qualitatively. Four central sections were microradiographed with the aid of faxitron (Cabinet X-ray system, Hewlett-Packard, Buffalo Grove, IL, USA) using KODAK Industrex film (100NIF, SR 45). The microradiographs (Fig. 1) were analyzed by QWin image analysis program (Leica, Bensheim, Germany) using a digital camera (Leica DC300F) and a zoom stereo microscope (Leica MZ75). The following cortical and trabecular parameters were measured: mean (ventral and dorsal) cortical width, cortical area and cortical density, endosteal trabecular density, number of trabecular nodes, number of nodes per $\mathrm{mm}^{2}$ and trabecular width (Fig. 2).

\section{Gene Expression Analyses}

The sixth vertebral body (L6) was homogenized using micro-dismembrator S (Sartorius, Goettingen, Germany). Total RNA was extracted with the aid of RNeasy ${ }^{\mathrm{TM}}$ Mini Kit (Qiagen, Hilden, Germany) and assessed by a photometer (Biometra, Goettingen, Germany). RNA samples (100ng) were then reverse-transcribed using Superscript ${ }^{\mathrm{TM}}$ RNase Hreverse transcriptase (Promega, Mannheim, Germany). Expression of rat genes, alkaline phosphatase (Alp1), osteocalcin (Oc), insulin-like growth factor-1 (Igf-1), receptor activator of nuclear factor $\mathrm{kB}$ ligand (Rankl), osteoprotegerin (Opg) were determined by quantitative realtime polymerase chain reaction (qRT-PCR) based on SYBR Green detection using iCycler (CFX96, Bio-Rad Laboratories, Munich, Germany). Ready-to-use primer pairs were obtained from Qiagen (QuantiTect ${ }^{\circledR}$ Primer Assays, Hilden, Germany). Relative gene expression was calculated using $2^{-\Delta \Delta C T}$ method [21] for each gene of interest relative to the value observed in intact group. In the intact group $(\mathrm{n}=$ 10), male rats were intact non-orchiectomized, nonosteotomized, untreated, maintained under the same conditions as the treatment groups, were of the same age and 

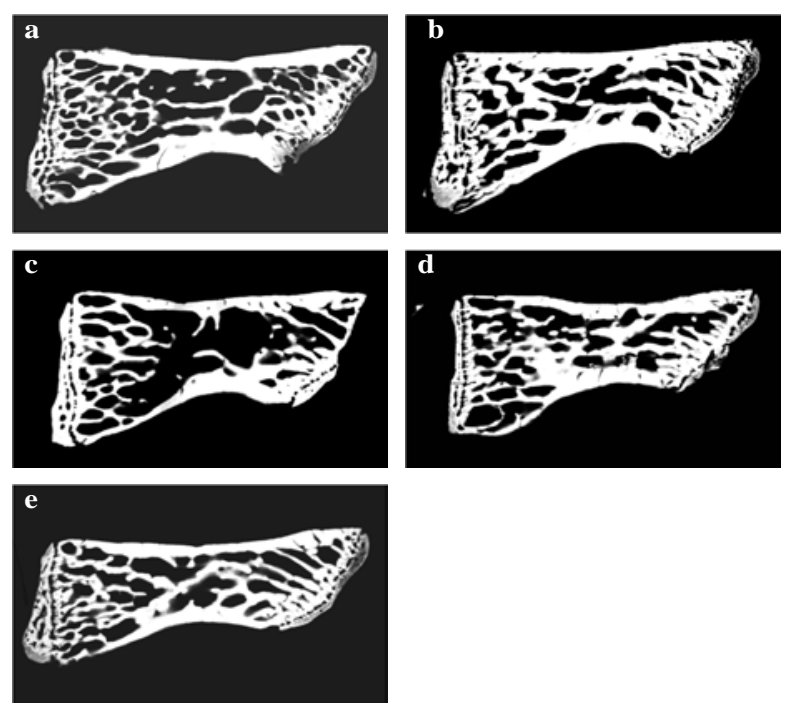

Fig. (1). Images of microradiographed sagital sections of L1 made after 5-week treatments in groups: (a) sham, (b) sham PTH/24h, (c) Orx, (d) Orx PTH/24h, (e) Orx PTH/48h.

had a comparable body weight. Reference gene was $\beta-2$ microglobulin.

\section{Serum Analyses}

Serum analyses were conducted at the Department of Clinical Chemistry, University of Goettingen. Serum testosterone level was measured using liquid chromatography tandem mass spectrometry with the aid of a Quattro Premier XE Micromass-System (Waters). Serum osteocalcin (OC) was determined by electrochemiluminiscence immunoassay analy- ses and alkaline phosphotase (ALP) by colorimetric assay using automated chemistry analyzer (Roche/Hitachi Modular) and commercially available kits (Roche Diagnostics GmbH, Mannheim, Germany).

\section{Statistical Analyses}

Analyses of variance (ANOVA, P < 0.05) were applied to reveal the effect of PTH on bone parameters (SAS 9.1; SAS Institute, Cary, NC). Differences between individual means were estimated using Schéffe-test $(\mathrm{P}<0.05)$. Data are shown as means and standard error of the means (SEM). Kruskal-Wallis test and Dunn multiple comparison test were used for analyses of relative gene expression (GraphPad Prism 4.0; San Diego, CA).

\section{RESULTS}

\section{Flat-Panel Volume Computed Tomography (fpVCT)}

Cortical BMD increased significantly after PTH treatments in both sham and Orx groups. In "PTH/48h" group, cortical BMD was lower than in "PTH/24h" group, being however higher than in the untreated sham group (Table 1). Cancellous BMD did not change significantly among the treatment groups. The differences between sham and Orx rats were not revealed.

\section{Ashing}

Ash to volume ratio increased significantly after daily PTH administration in Orx rats (Table 1). Among other treatment groups, inorganic weight did not differ significantly. The molar ratio of calcium to orthophosphate did not change after PTH treatments.

Table 1. Analyses of Lumbar Vertebral Bodies (L) in Orchiectomized (Orx) or Sham Rats Treated Either with PTH Every 24h (PTH/24h), Every 48h (PTH/48h) or given Vehicle During 5 Weeks. At Least 10 Replications Per Treatment Group were Done

\begin{tabular}{|c|c|c|c|c|c|c|c|c|c|c|}
\hline & \multicolumn{2}{|c|}{ Sham } & \multicolumn{2}{|c|}{ Sham PTH/24h } & \multicolumn{2}{|c|}{ Orx } & \multicolumn{2}{|c|}{ Orx PTH/24h } & \multicolumn{2}{|c|}{ Orx PTH/48h } \\
\hline & Mean & SEM & Mean & SEM & Mean & SEM & Mean & SEM & Mean & SEM \\
\hline \multicolumn{11}{|l|}{$f p V C T(L 3) \mathrm{mg} / \mathrm{cm} 3$} \\
\hline Cortical BMD & $463^{\mathrm{a}}$ & 4 & $510^{\mathrm{c}}$ & 4 & $451^{\mathrm{a}}$ & 3 & $495^{\mathrm{b}}$ & 8 & $477^{\mathrm{d}}$ & 4 \\
\hline Cancellous BMD & 239 & 1 & 237 & 1 & 237 & 1 & 242 & 2 & 239 & 1 \\
\hline \multicolumn{11}{|l|}{ Ashing (L2) } \\
\hline Ash/Volume $\left(\mathrm{mg} / \mathrm{mm}^{3}\right)$ & $1.09^{\mathrm{ab}}$ & 0.05 & $1.28^{\mathrm{bc}}$ & 0.12 & $1.02^{\mathrm{a}}$ & 0.07 & $1.36^{\mathrm{c}}$ & 0.11 & $1.16^{\mathrm{ac}}$ & 0.06 \\
\hline $\mathrm{Ca}^{2+} / \mathrm{PO}_{4}{ }^{3-}$ & 1.91 & 0.26 & 1.79 & 0.14 & 2.18 & 0.18 & 1.95 & 0.14 & 1.73 & 0.15 \\
\hline \multicolumn{11}{|l|}{ Biomechanics (L4) } \\
\hline Stiffness $(\mathrm{N} / \mathrm{mm})$ & 183 & 25 & 247 & 19 & 194 & 27 & 264 & 31 & 220 & 21 \\
\hline Yield load (N) & $232^{\mathrm{a}}$ & 17 & $376^{\mathrm{b}}$ & 12 & $239^{a}$ & 16 & $324^{\mathrm{bc}}$ & 31 & $297^{\mathrm{c}}$ & 17 \\
\hline Fmax $(\mathrm{N})$ & $252^{\mathrm{a}}$ & 17 & $378^{\mathrm{b}}$ & 11 & $254^{\mathrm{a}}$ & 13 & $338^{\mathrm{bc}}$ & 25 & $312^{\mathrm{c}}$ & 16 \\
\hline \multicolumn{11}{|l|}{ Histology (L1) } \\
\hline Cortical width (mm) & $0.40^{\mathrm{a}}$ & 0.02 & $0.52^{\mathrm{b}}$ & 0.02 & $0.40^{\mathrm{a}}$ & 0.01 & $0.49^{\mathrm{b}}$ & 0.03 & $0.50^{\mathrm{b}}$ & 0.02 \\
\hline Cortical area $(\mathrm{mm})$ & $7.3^{\mathrm{a}}$ & 0.6 & $10.7^{\mathrm{c}}$ & 0.2 & $6.9^{\mathrm{a}}$ & 0.3 & $8.7^{\mathrm{b}}$ & 0.5 & $9.4^{\mathrm{b}}$ & 0.3 \\
\hline Cortical density (\%) & $92^{\mathrm{a}}$ & 1 & $95^{\mathrm{b}}$ & 1 & $93^{\mathrm{a}}$ & 1 & $95^{\mathrm{b}}$ & 1 & $94^{\mathrm{b}}$ & 0.3 \\
\hline Trabecular density (\%) & $44^{\mathrm{a}}$ & 2 & $59^{\mathrm{b}}$ & 2 & $41^{a}$ & 1 & $57^{\mathrm{b}}$ & 2 & $50^{\mathrm{c}}$ & 2 \\
\hline Trabecular nodes (n) & $110^{\mathrm{a}}$ & 5 & $97^{\mathrm{ab}}$ & 4 & $87^{\mathrm{bc}}$ & 4 & $92^{\mathrm{bc}}$ & 4 & $82^{c}$ & 4 \\
\hline Trabecular nodes $/ \mathrm{mm}^{2}$ & $4.4^{\mathrm{a}}$ & 0.3 & $3.9^{\mathrm{ac}}$ & 0.2 & $3.2^{\mathrm{b}}$ & 0.1 & $4.6^{\mathrm{a}}$ & 0.4 & $3.4^{\mathrm{bc}}$ & 0.1 \\
\hline Trabecular width $(\mu \mathrm{m})$ & $5.7^{\mathrm{a}}$ & 0.1 & $7.3^{\mathrm{b}}$ & 0.3 & $5.8^{\mathrm{a}}$ & 0.1 & $7.2^{\mathrm{b}}$ & 0.2 & $6.5^{\mathrm{c}}$ & 0.2 \\
\hline
\end{tabular}

\footnotetext{
${ }^{\text {abcd }}$ within row between treatment groups means with different superscripts differ $(\mathrm{P}<0.05$, Scheffé-test $)$
} 


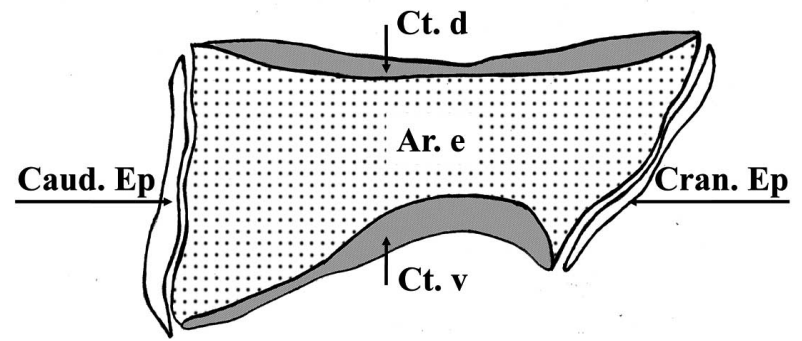

Fig. (2). Schematic diagram of measured cortical and trabecular bones of L1. Caud.Ep, caudal epiphysis and Cran.Ep, cranial epiphysis were not included in the analyses. Ct.d, cortical bone dorsal and Ct.v, cortical bone ventral were analyzed combined. Trabecular bone parameters were measured within endosteal area (Ar.e).
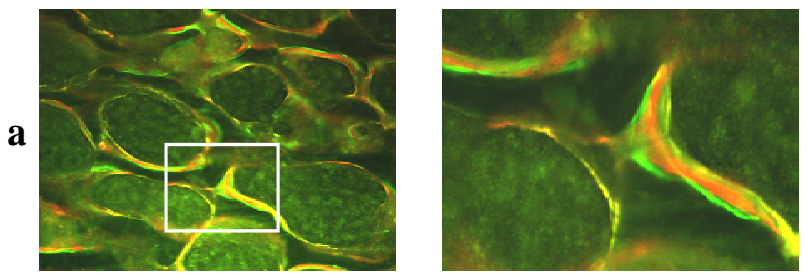

$\mathbf{b}$
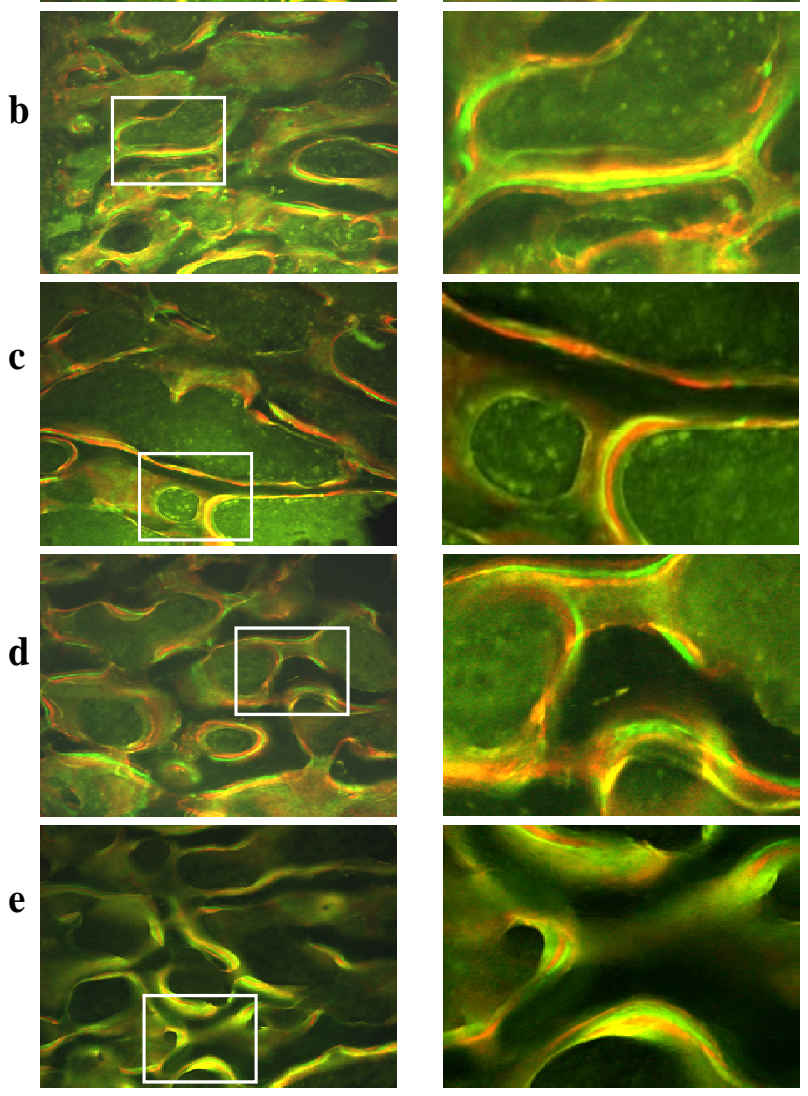

Fig. (3). Fluorochrome-labeled sections of L1 made after 5-week treatments in groups: within row (a) sham, (b) sham PTH/24h, (c) Orx, (d) Orx PTH/24h, (e) Orx PTH/48h. Rectangular frames within the first column indicate the region shown in the second column.

\section{Biomechanical Analyses}

Yield load and Fmax increased in Orx PTH/24h group to the enhanced level of sham rats treated with PTH (Table 1). In Orx PTH/48h group, the increase was less. However, yield load and Fmax were at a higher level in this group than those measured in sham group. Stiffness did not differ between the groups. There was no difference in the biomechanical properties of L4 between Orx and sham rats.

\section{Histological analyses}

PTH treatment resulted in an increased trabecular density, thicker cortical and trabecular structures (Fig. 1 b,d,e). In Orx rats, trabecular network was less dense than in sham rats (Fig. 1 a,c). Qualitative analyses of fluorochrome labeled sections showed that both sham and Orx rats treated with PTH had thicker apposition bands and thereby more intense bone formation than untreated rats (Fig. 3).

Cortical width, area and density increased significantly after PTH treatment in all groups (Table 1), whereas, between Orx and sham rats, the differences were not found. Trabecular parameters improved after PTH administration in both sham and Orx group. The effect was less if PTH was applied every $48 \mathrm{~h}$. In Orx rats, number of trabecular nodes was lower compared to that observed in sham rats.

\section{Gene Expression Analyses}

There were no significant differences in the expression of bone genes in vertebral body among the treatment groups (Fig. 4). However, the tendency of Oc and Rankl gene expression to increase after PTH treatments was observed.

\section{Serum Analyses}

The serum testosterone significantly decreased to the level around zero in Orx rats $(0.02 \mathrm{ng} / \mathrm{mL}, \mathrm{SEM}=0.003)$, whereas in sham rats it was $1.5 \mathrm{ng} / \mathrm{mL}(\mathrm{SEM}=0.2)$ on average. PTH treatments significantly enhanced OC level in all rats and did not change ( $\mathrm{P}>0.05)$ ALP activity [15].

\section{DISCUSSION}

The intent of the present study was to investigate the effect of every $48 \mathrm{~h}$ PTH (1-34) treatment on lumbar spine in osteopenic aged male rats and compare it with every $24 \mathrm{~h}$ application of the teriparatide. Orchiectomized rats display deleterious changes in bone within 4 weeks after orchiectomy and may be used for osteoporotic studies [22, 23].

In the present study, it was shown that every $24 \mathrm{~h}$ treatment with PTH improved cortical and trabecular densities, enlarged cortical area and trabecular width, enhanced biomechanical properties and inorganic weight of lumbar spine in both Orx and sham rats. Daily PTH treatment has been reported to have positive effect on both trabecular and cortical bone in osteoporotic subjects [24].

The administration of PTH every $48 \mathrm{~h}$ in Orx rats had beneficial effect on vertebral spine too, however, to a lesser extent. Nevertheless, bone properties were improved to the level observed in healthy rats. Similar regime-depending effect has been reported on the healing of tibia osteotomy as well as serum osteocalcin level in these rats [15] and on vertebral body in ovariectomized female rats of 6 months of age [17]. Interestingly, in the latter, PTH improved osteotomy healing irrespectively of administration regime [17]. Variations in bone mineral density (BMD) and bone disorder related to osteoporosis are largely determined genetically, however, the mechanisms of gene action are not 
a
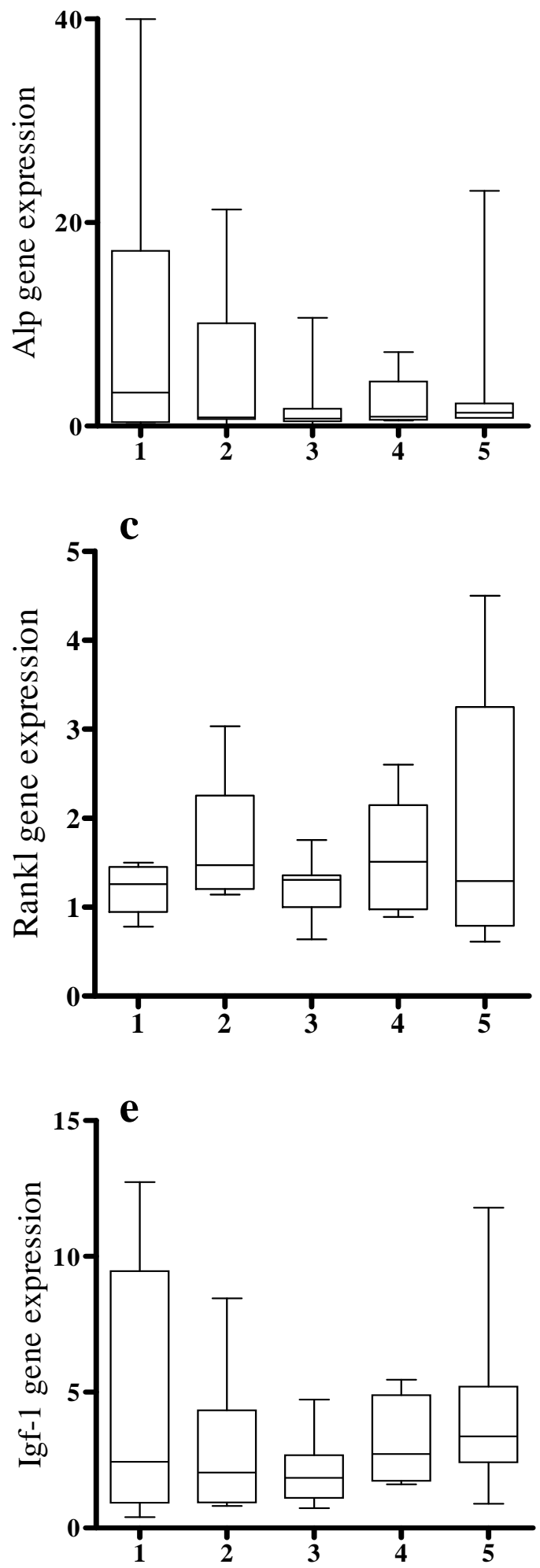

b
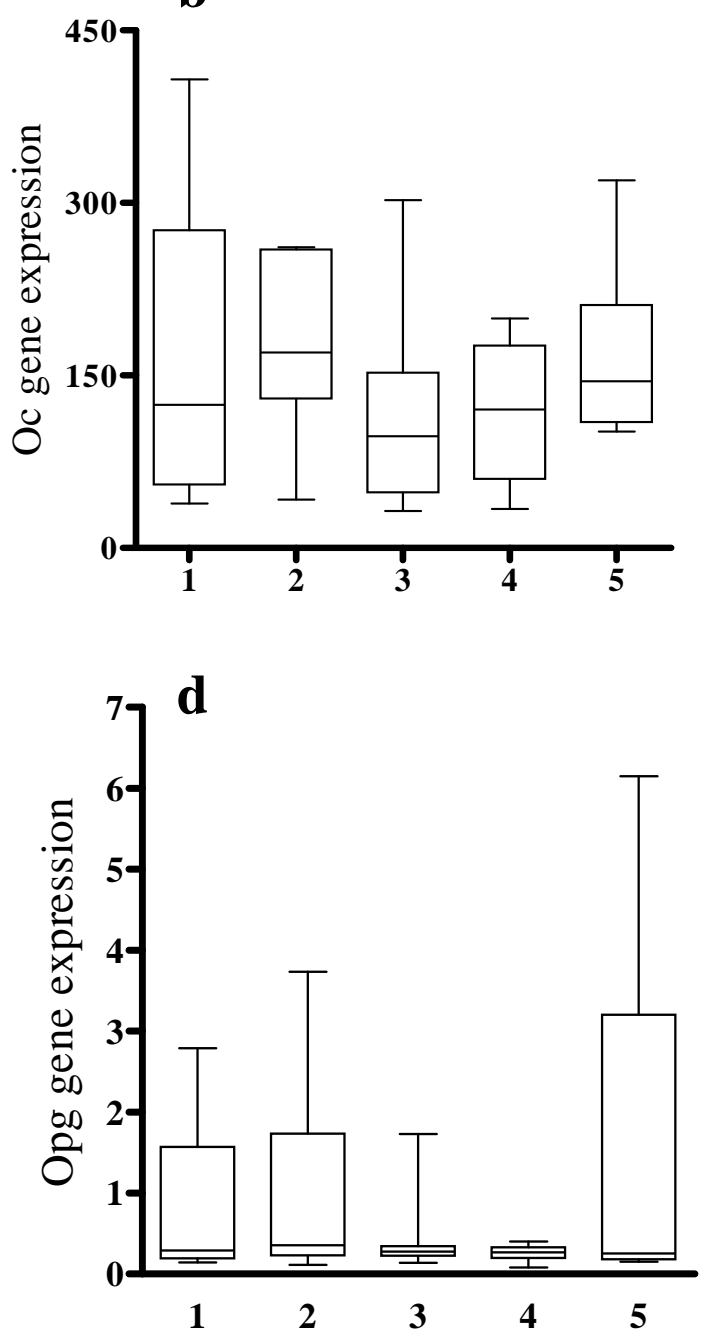

Fig. (4). Box plot illustrating relative mRNA expression level of (a) Alp, (b) Oc, (c) Rankl (d) Opg, (e) Igf-1 genes in L6 calculated using 2 $\triangle \triangle \mathrm{CT}$ method relative to gene expression in untreated rats taken as 1. On the X-axis treatment groups: (1) sham, (2) sham PTH/24h, (3) Orx, (4) Orx PTH/24h, (5) Orx PTH/48h. At least 8 replications per treatment group were done. The differences were not significant $(\mathrm{P}>0.05$, Dunn test).

established so far [25]. The PTH administration slightly, though not significantly enhanced bone formation and resorption genes in lumbar spine in the present study, and correspondently caused significant up-regulation of Igf-1, Opg and Rankl genes in the callus of tibia in these rats [15]. On the contrary, in ovariectomized (Ovx) rats no changes 
were found in mRNA gene expression in the callus [14], whereas in lumbar vertebral body, bone genes were upregulated after PTH treatment [17]. In the present study, PTH effect on spine was not blunt by orchiectomy, being similar effective in both sham and Orx rats, whereas, stimulation of tibia healing by PTH was more efficient in sham rats [15]. Turner et al. [23] reported that gonadal hormones exerted distinct effects on bone metabolism in male and female rats. In Ovx rats, loss of cancellous bone results from increased osteoclast-mediated bone resorption, whereas diminished bone formation is at least a contributing factor in Orx rats [23]. Various responses to PTH by different anatomic sites have been reported [10]. Additionally, the differences in age of the animals may contribute to the observed PTH effect.

Applying fpVCT analyses, the improved mineral density was detected solely in cortical bone after PTH treatments, whereas in trabecular bones this was not seen. However, the histomorphological analysis showed the significantly enhanced trabecular density in all PTH treated rats. This indicated that computed tomographical analysis could not adequately reflect important structural improvements that enhanced the biomechanical stability of bone tissue in these rats. The micro-computed tomography which provides highresolution assessments of trabecular microstructure could be a more effective means for analyses of bone tissue in rat model.

Studying the effect of orchiectomy on bone, the developing of osteopenia was confirmed. Histological analyses revealed reduced trabecular number in Orx rats. However, cortical bone parameters were less affected by androgen deficiency. It is known that cancellous bone is more affected by gonadal hormone depletion than cortical bone $[22,23]$. This may explain unaltered biomechanical properties of lumbar vertebral body in Orx rats.

Concluding, every 24h PTH administration improved the osteopenic bone already after 5 weeks so that the level of sham, i.e. healthy group was achieved and in most cases even surpassed. The every $48 \mathrm{~h}$ application resulted in significant improvement of cortical structure, biomechanical parameters and trabecular density in comparison to the untreated sham group. In sham group, PTH affected bone also anabolically. Considering limitations of daily treatment and possible side effects [11], the application of PTH with less frequency (e.g. every 48h) may serve as an option for osteoporosis treatment in male subjects. The comparisons with other studies showed that the effectiveness of PTH treatment is dependent on age and hormonal status of the subjects; different anatomic sites responded variously to PTH treatment. These indications may be useful in perspective for further clinical studies conducted in osteoporotic patients.

\section{ACKNOWLEDGEMENTS}

This study was supported by the AO International Foundation (S-100). The authors thank R. Castro-Machguth and A. Witt for their help.

\section{CONFLICT OF INTEREST}

The authors confirm that this article content has no conflicts of interest.

\section{REFERENCES}

[1] Lindsay R, Silverman SL, Cooper C, et al. Risk of new vertebral fracture in the year following a fracture. JAMA 2001; 285: 320-3.

[2] Melton LJ 3rd, Alothman KJ, Khosla S, Achenbach SJ, Oberg AL Zincke H. Fracture risk following bilateral orchiectomy. J Urol 2003; 169: 1747-50.

[3] Guggenbuhla P. Osteoporosis in males and females: is there really a difference? Joint Bone Spine 2009; 76: 595-601.

[4] Melton LJ 3rd, Thamer M, Ray NF, et al. Fractures attributable to osteoporosis: report from the National Osteoporosis Foundation. J Back Musculoskelet Rehabil 1997; 12:16-23.

[5] Häussler B, Gothe H, Göl D, Glaeske G, Pientka L, Felsenberg D. Epidemiology, treatment and costs of osteoporosis in Germany--the BoneEVA Study. Osteoporos Int 2007; 18: 77-84.

[6] Meryn S. Undertreatment of osteoporosis in men. Arch Intern Med 2005; 165: 241.

[7] Compston JE. Skeletal actions of intermittent parathyroid hormone: Effects on bone remodeling and structure. Bone 2007; 40: 1447-52.

[8] Hodsman A, Papaioannou A, Cranney A. Clinical practice guidelines for the use of parathyroid hormone in the treatment of osteoporosis. CMAJ 2006; 175: 48-51.

[9] Bellido T, Ali AA, Plotkin LI, et al. Proteasomal degradation of Runx2 shortens parathyroid hormone-induced anti-apoptotic signaling in osteoblasts. A putative explanation for why intermittent administration is needed for bone anabolism. J Biol Chem 2003; 278: 50259-72.

[10] Crandall C. Parathyroid hormone for treatment of osteoporosis. Arch Intern Med 2002; 162: 2297-309.

[11] Devogelaer J-P, Boutsen Y, Manicourt DH. Biologicals in osteoporosis: teriparatide and parathyroid hormone in women and men. Curr Osteoporos Rep 2010; 8: 154-61.

[12] Nakajima A, Shimoji N, Shiomi K, et al. Mechanisms for the enhancement of fracture healing in rats treated with intermittent low-dose human parathyroid hormone (1-34). J Bone Miner Res 2002; 17: 2038-47.

[13] Nozaka K, Miyakoshi N, Kasukawa Y, Maekawa S, Noguchi H, Shimada Y. Intermittent administration of human parathyroid hormone enhances bone formation and union at the site of cancellous bone osteotomy in normal and ovariectomized rats. Bone 2008; 42: 90-7.

[14] Komrakova M, Stuermer EK, Werner C, et al. Effect of human parathyroid hormone hPTH (1-34) applied at different regimes on fracture healing and muscle in ovariectomized and healthy rats. Bone 2010; 47: 480-92.

[15] Komrakova M, Krischek C, Wicke $\mathrm{M}$, et al. Influence of intermittent administration of parathyroid hormone on muscle tissue and bone healing in orchiectomized rats or controls. J Endocrinol 2011; 209: 9-19

[16] Tezval, M, Serferaz G, Rack T, et al. Effect of parathyroid hormone on hypogonadism induced bone loss of proximal femur of orchiectomized rat. World J Urol 2011; 29: 529-34.

[17] Komrakova M, Sehmisch S, Stuermer KM, Stuermer EK. The effect of parathyroid hormone on bone. In: Kirkby Bott J, Ed. Parathyroid: anatomy, functions and disorders. NY: Nova Science Publishers, Incorporated 2012.

[18] Stuermer EK, Sehmisch S, Rack T, et al. Estrogen and raloxifene improve metaphyseal fracture healing in the early phase of osteoporosis. A new fracture-healing model at the tibia in rat. Langenbeck Arch Surg 2010; 395: 163-72.

[19] Sehmisch S, Dullin C, Zaroban A, et al. The use of flat panel volumetric computed tomography (fpVCT) in osteoporosis research. Acad Radiol 2009; 16: 394-400.

[20] Sehmisch S, Erren M, Rack T, et al. A new biomechanical test for intact rat lumbar vertebral bodies to study antiosteoporotic drugs. Short term effects of parathyroid hormone on rat lumbar vertebrae. Spine 2009; 34: 2014-21.

[21] Livak KJ, Schmittgen TD. Analysis of relative gene expression data using real-time quantitative PCR and the $2-\Delta \Delta \mathrm{CT}$ method. Methods 2001; 25: 402-8.

[22] Wink CS, Felts WJL. Effects of castration on the bone structure of male rats: a model of osteoporosis. Calcif Tissue Int 1980; 32: 7782.

[23] Turner RT, Hannon KS, Demers LM, Buchanan J, Bell NH. Differential effects of gonadal function on bone histomorphometry in male and female rats. J Back Musculoskelet Rehabil 1989; 4: $557-63$. 
[24] Jiang Y, Zhao JJ, Mitlak BH, Wang O, Genant HK, Eriksen EF. Recombinant human parathyroid hormone (1-34) [teriparatide] improves both cortical and cancellous bone structure. J Bone Miner Res 2003; 18: 1932-41.
[25] Dvornyk V, Recker RR, Deng H-W. Gene expression studies of osteoporosis: implications for microarray research. Osteoporos Int 2003; 14: 451-61.

Received: May 07, 2012

Revised: June 08, 2012

Accepted: June 15, 2012

(C) Komrakova et al.; Licensee Bentham Open.

This is an open access article licensed under the terms of the Creative Commons Attribution Non-Commercial License (http://creativecommons.org/licenses/by-nc/3.0/) which permits unrestricted, non-commercial use, distribution and reproduction in any medium, provided the work is properly cited. 